\title{
Sexual dimorphism involved in the mesiodistal and buccolingual di- mensions of permanent teeth
}

\author{
Ticiana Medeiros Sabóia ${ }^{1}$, Patricia Nivoloni Tannure ${ }^{2}$, Ronir Raggio Luiz ${ }^{5}$, Marcelo de Castro Costa ${ }^{1}$, Jose Mauro Granjeiro ${ }^{3}$, Erika Calvano Küch- \\ ler $^{3}$, Leonardo Santos Antunes ${ }^{4}$
}

${ }^{1}$ Department of Pediatric Dentistry and Orthodontics, School of Dentistry, Federal University of Rio de Janeiro, RJ, Brazil

${ }^{2}$ Discipline of Pediatric Dentistry, School of Dentistry, Veiga de Almeida University, RJ, Brazil

${ }^{3}$ Unit of Clinical Research, Fluminense Federal University, Niterói, RJ, Brazil

${ }^{4}$ Department of Specific Formation, School of Dentistry, Fluminense Federal University, Nova Friburgo, RJ, Brazil

${ }^{5}$ Institute of Public Health Studies, Federal University of Rio de Janeiro, RJ, Brazil

\section{Abstract}

Studies indicate that tooth crown diameters are clinical markers for sex differentiation. Therefore, the aim of this study was to assess the degree of sexual dimorphism in different teeth. Maximum mesiodistal (MD) and buccolingual (BL) dimensions of 2400 permanent teeth from 100 pretreatment orthodontic dental study casts and clinical records ( 50 males and 50 females) from the Department of Pediatric Dentistry and Orthodontics, Federal University of Rio de Janeiro, Brazil, were examined. Comparison of the MD and BL dimensions between males and females was performed using the Student's $t$ test with alpha 0.05, effect size, and discriminant function analysis. Comparisons in MD and BL widths between sexes demonstrated that the combined mean in the female group presented reduction when compared with the male group, except for the BL dimension of tooth 26 . In regard to the MD dimensions, statistically significant differences were observed in various dental groups. The greatest sexual dimorphism was observed in the left mandibular canine $(p<0.001)$ with effect size over $0.8(0.94)$, which characterizes large effect. In BL dimension, numerous teeth demonstrated statistical differences between the sexes. Our findings reinforced the magnitude of sexual dimorphism in tooth size, and, in addition, highlighted the differences in specific dental groups.

\section{Introduction}

The sexual dimorphism is explained by different effects of the human X and Y chromosome genes on various somatic features, such as the frequency of some dental anomalies and the tooth crown size [1-3].

Various explanations for tooth-size dimorphism between males and females have been proposed: the differences in hormonal balance [4], the effect of the Y chromosome in increasing mitotic activity within the developing dental lamina, and the fact that the chromosome $\mathrm{X}$ is known to be involved in the enamel formation [2]. Some authors suggested that this difference is due to the amount of enamel [5], while others found significant differences in the amounts of dentine [6].
The tooth crown size is a valuable tool and provides significant information on human evolution [7] and biological alterations [8], a in forensic evaluation $[9,10]$ and clinical odontology [11]. Tooth crown diameters are reasonably accurate predictors of sex and are good adjuncts for sex differentiation [12]. Although the degree of dimorphism varies within different populations, generally, males have larger tooth crowns than females [13-16].

Therefore, the present study was conducted to assess the degree of sexual dimorphism in permanent teeth of patients recruited at the Federal University of Rio de Janeiro, Brazil.

\section{Materials and Methods}

A total of 2400 permanent teeth from 100 pretreatment orthodontic dental study casts
Citation: Sabóia TM, Tannure PN, Luiz RR, Costa MC, Granjeiro JM, Küchler EC, Antunes LS. (2013) Sexual dimorphism involved on the mesiodistal and buccolingual dimensions of permanent teeth. Dentistry 3000 1:a003 doi: 10.5195/d3000.2013.10

Received: May 06, 2013

Accepted: November 01, 2013

Published: November 19, 2013

Copyright: (C2013 Sabóia et al. This is an open-access article licensed under a Creative Commons Attribution 3.0 United States license.

License.

Email: leonardoantunes@id.uff.br and clinical records from the Department of Pediatric Dentistry and Orthodontics, Federal University of Rio de Janeiro, Brazil, were examined. Patients with underlying syndromes and oral clefts were not included in this study. Patients who had their pretreatment orthodontic records performed between 2000 to 2010 were available for this study. Fifty males and 50 females were selected at random. Ethical approval was obtained from the Human Ethics Committee of the Health Department of the city of Rio de Janeiro, Rio de Janeiro, Brazil (113/09). Written informed consent was obtained from all participating individuals or parents/legal guardians.

The population included in this study resides in the metropolitan area of Rio de Janeiro, Brazil, and is comprised of a mixture of Caucasians (mainly European desce-

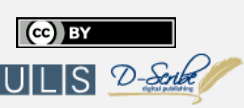

This work is licensed under a Creative Commons Attribution 3.0 United States License.

This site is published by the University Library System, University of Pittsburgh as part of its D-Scribe Digital Publishing Program and is cosponsored by the University of Pittsburgh Press. 


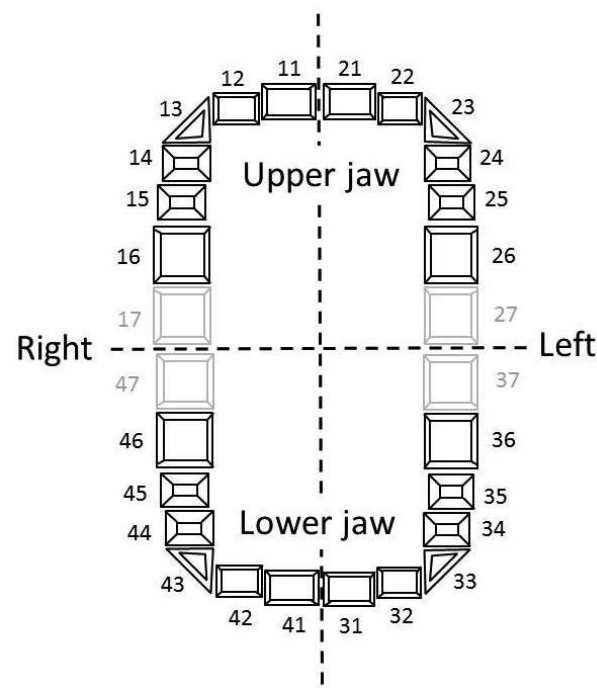

Figure 1. Dental diagram. This diagram represents the permanent dentition. Second molars are presented in gray color since they were not evaluated in this work. Third molars are not presented in this diagram. This diagram is labeled according to the Federation Dentaire Internationale Numbering System.

ndants (53.6\%) and African descendants (33.6\% obviously mixed Portuguese, $12.3 \%$ not obviously mixed Africans). The remaining $0.5 \%$ of the population is Amerindian or Asian descendants. The ethnicity was based on the self-reported description.

\section{Assessment of tooth dimensions}

Dental casts were used to obtain data regarding tooth dimensions. A dental diagram with the tooth nomenclature used in this work is presented in Figure 1. Dental casts were excluded from assessment if they fell into one of the following criteria: teeth with restorations extending both for the mesiodistal and for the buccolingual surfaces, teeth displaced or crowded, and teeth not fully erupted. Second and third molars were excluded due to the young age of many of the subjects. Maximum mesiodistal (MD) and buccolingual (BL) dimensions of fully erupted permanent teeth were measured to the nearest 0.1 millimeters using the digital Mitutoyo caliper. MD is defined as the maximum distance between the most mesial and the most distal point of the crown, whereas BL is defined as the maximum distance between the most lingual/palatal and the most buccal/labial point of the crown. The dimensions were recorded for each tooth using the method proposed by Moorrees and Reed [17].

All measurements were undertaken by one operator (T.M.S.), with a strict criterion in order to reduce variation. Five models were analyzed per day during two months to prevent depletion of the operator. Each tooth was measured three times and, if the

Table1.Characteristics of the individuals studied.

\begin{tabular}{|l|c|c|c|}
\cline { 2 - 4 } \multicolumn{1}{c|}{} & Male & Female & p-value \\
\hline Mean age (Standard Deviation) & $17.2( \pm 4.6)$ & $19.8( \pm 6.3)$ & $0.02 *$ \\
\hline Ethnicity (\%) & $37(74 \%)$ & $30(60 \%)$ & $0.1^{* *}$ \\
\hline Caucasian & $13(26 \%)$ & $20(40 \%)$ & \\
\hline African descendant & \multicolumn{2}{|c|}{} \\
\hline
\end{tabular}

Note: ${ }^{*}$ T-test; ${ }^{* *}$ Chi-square test; bold emphasis indicates statistical significance $(p \leq 0.05)$.

measurements differed by more than 0.2 millimeters, was measured three times again.

\section{Statistical Analysis}

An intra-class correlation coefficient was calculated to assess random error of intraobserver variability. The dental casts of ten subjects were selected and all tooth measurements were assessed on two occasions at least two weeks apart. The level of agreement was equal to 0.99 , indicating an excellent level of reproducibility of the tooth dimension measurements. The descriptive values of MD and BL dimensions
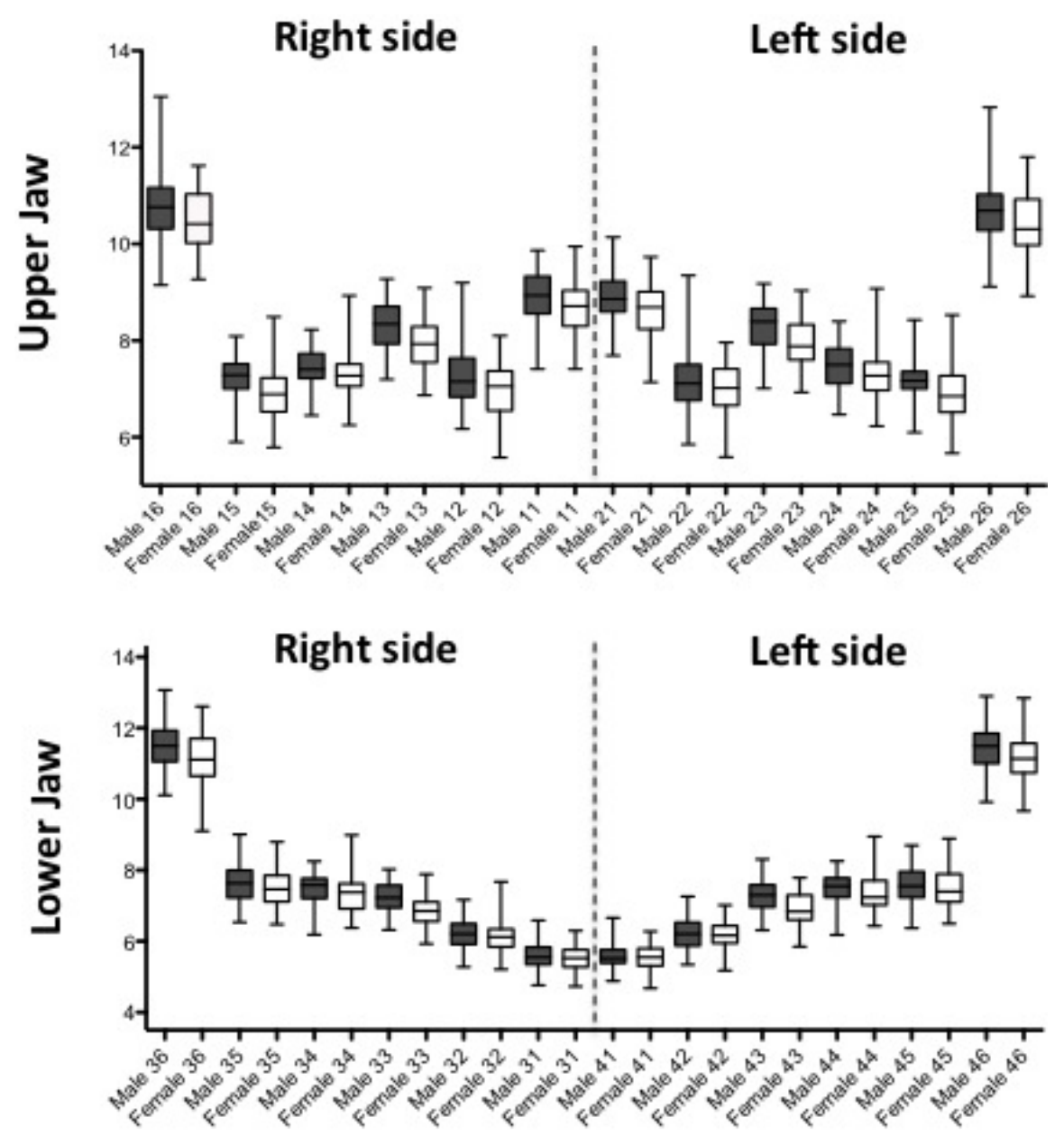

Figure 2. Box plot showing quartiles and mean of the mesiodistal dimensions of upper and lower teeth. Statistical difference between genders is represented in Table 2. Tooth numbers correlate to the numbers in Figure 1. (means and standard deviations) were recorded. Comparison between MD and BL dimensions of the male and female permanent teeth was performed using the Student's $t$ test with an alpha of 0.05. Effect sizes were calculated as the difference between the means (measurements for each tooth in relation to sex) divided by standard deviation of either group. The widely used benchmarks, suggested by Cohen [18], indicated the magnitude of the change observed. That is, effect sizes of 0.2 were taken to be small, 0.5 to be moderate, and 0.8 or above to be large. Comparison between MD 


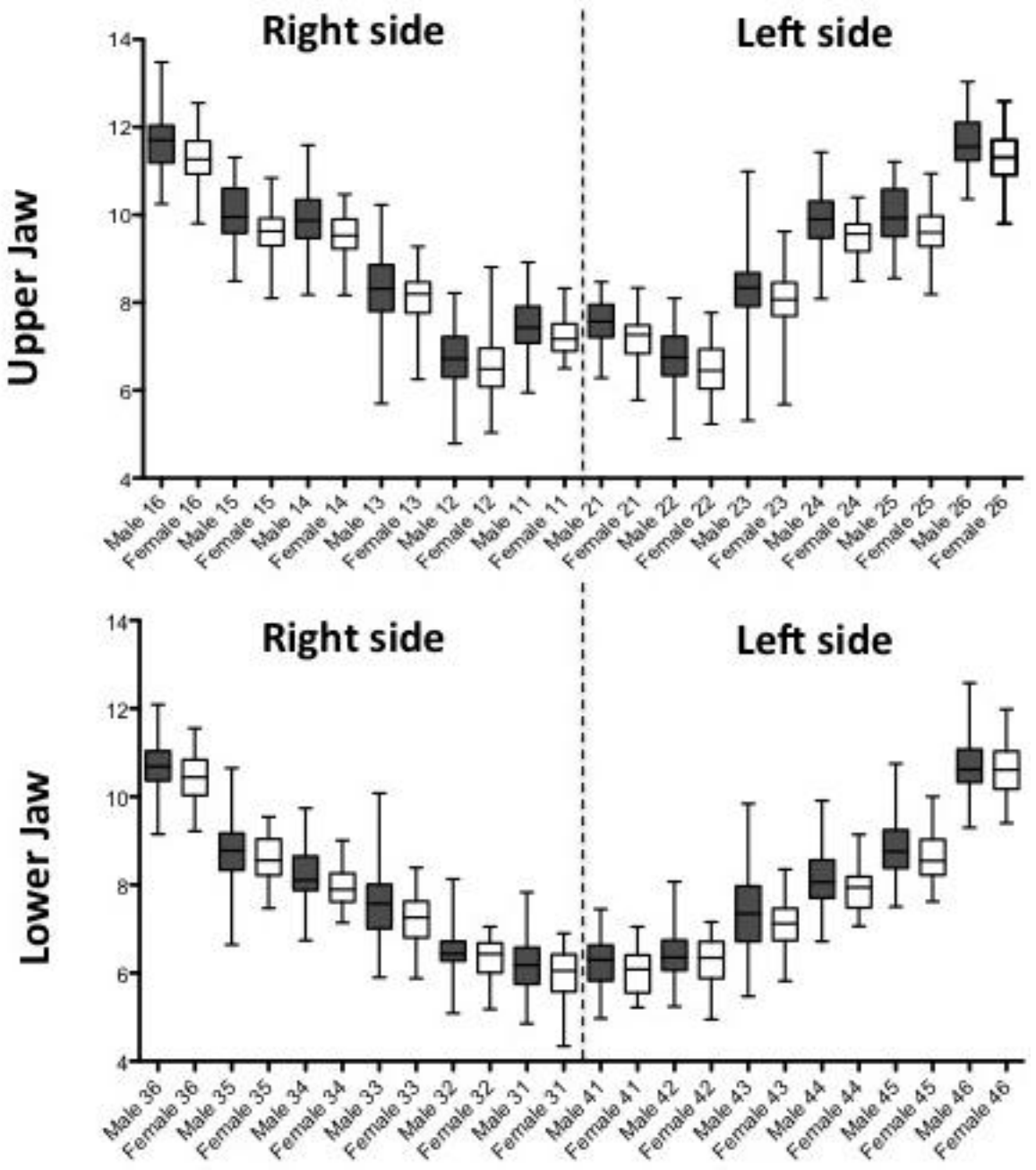

Figure 3. Box plot showing quartiles and mean of the buccolingual dimensions of upper and lower teeth. Statistical difference between genders is represented in Table 2. Tooth numbers correlate to the numbers in Figure 1.

and BL dimensions of the Caucasian and African descendants' permanent teeth was also performed using the Student's $t$ test with an alpha of 0.05 . For the dimensions that were different between ethnicities, logistic regression analyses were performed including ethnicity as covariates. Results were reported according to the STROBE guidelines for cohort.

\section{Results}

The univariate analysis showed that there are no significant differences in ethnicity between male and female $(p=0.1)$. The demographic characteristics of the studied individuals are summarized in Table 1.

In both comparisons, MD and BL widths between sex demonstrated that the combined mean of each tooth in the female group presented reduction when compared with the male group. Out of the 48 variables measured, male teeth exceeded female teeth significantly in 26 variables $(p<0.05)$. Of these, 13 belonged to the maxillary and 13 were BL dimensions.

In regard to the MD dimensions, statistically significant differences were observed in various teeth, the greatest of which were observed in the mandibular left canine (33) $(\mathrm{p}<0.001)$, with effect size over $0.8(0.94)$, and in the mandibular right canine (43) $(\mathrm{p}<0.001)$, with effect size over $0.8(0.88)$. In BL dimension, many teeth demonstrated statistical differences between the sexes. These results were observed in Table 2. A graphical representation of MD and BL dimensions are also provided in Figure 2 and Figure 3.

In regard to the differences between the ethnicities, Caucasians presented statistically significant reduced dimensions in specifics cases. In males, differences were observed in the MD dimension of upper right second premolar (15) and in the BL dimension of upper right (12) and left (22) lateral incisor. In females, differences were ob- served in the MD dimension of the first molars $(16,26,36$ and 46) and the lower left lateral incisor (32). Differences were also observed in the BL dimensions of the lower second right premolar (45). The results of the logistic regression analyses for these dimensions, using the ethnicity as covariant, are presented in Table 3.

\section{DISCUSSION}

The general structure and morphology of the teeth are similar in both men and women, however, there are subtle differences, such as variation in dental size, that can give a clue about differences between the sexes. Following this pattern, teeth can be considered an important step for sex determination as they are resistant to postmortem destruction and fragmentation. The accessibility for measuring the dimensions of the teeth using morphometric devices would be a reliable method for solving medicolegal investigations and to identify victims of crime, natural disasters, and severe accidents.

In this study, we analyzed the degree of the sexual dimorphism in different teeth by measuring the maximum diameters, mesiodistal and buccolingual, of fully erupted permanent teeth from study casts. Our results raise an interesting possibility that could be used to clarify this difference. Measurement of the MD width of the mandibular and maxillary canines provides good evidence of sex identification due to dimorphism, since this measurement showed higher effect sizes than other teeth. These results are consistent with previous studies that found the canine to be one of the most dimorphic teeth [19-21].

It was previously proposed that the magnitude of the difference of canine size is not isolated and that there is a "field" of sexual dimorphism that includes the teeth adjacent to the canines (incisors and premolars) [22, 23]. Interestingly, this study provided evidence of strong difference between the first premolars (BL dimensions of 14, 24, 34, 44) and lateral incisors (MD dimension of 12 and $\mathrm{BL}$ dimension of 22 ) of males and females.

Regarding the difference in tooth size between men and women, MD and BL dimensions were smaller in females than males in almost all teeth, corroborating with previous studies [20,24].

Several studies have investigated the possible reasons for the morphological and developmental difference in teeth between men and women. Animal model studies suggested that specific genetic factors might be involved with specific types of tooth development [25]. According Schwartz and 
Table2. Effect size of the mesiodistal (MD) and buccolingual (BL) dimensions of the permanent teeth between male and female.

\begin{tabular}{|c|c|c|c|c|c|c|c|}
\hline \multirow[b]{2}{*}{ Tooth Type } & \multicolumn{2}{|c|}{ Male } & \multicolumn{2}{|c|}{ Female } & \multirow[b]{2}{*}{ Difference } & \multirow[b]{2}{*}{ Effect Size } & \multirow[b]{2}{*}{ p-value } \\
\hline & Mean & $\begin{array}{l}\text { Standard } \\
\text { Deviation }\end{array}$ & Mean & $\begin{array}{l}\text { Standard } \\
\text { Deviation }\end{array}$ & & & \\
\hline MD 33 & 7.24 & 0.41 & 6.85 & 0.42 & 0.39 & 0.94 & $<0.001$ \\
\hline MD 43 & 7.29 & 0.45 & 6.90 & 0.43 & 0.39 & 0.88 & $<0.001$ \\
\hline MD 13 & 8.32 & 0.50 & 7.94 & 0.50 & 0.38 & 0.76 & $<0.001$ \\
\hline MD 23 & 8.32 & 0.48 & 7.96 & 0.52 & 0.36 & 0.72 & 0.001 \\
\hline BL 25 & 9.99 & 0.69 & 9.55 & 0.58 & 0.44 & 0.69 & 0.001 \\
\hline BL 15 & 10.00 & 0.69 & 9.58 & 0.53 & 0.42 & 0.68 & 0.001 \\
\hline BL 21 & 7.53 & 0.54 & 7.21 & 0.47 & 0.32 & 0.63 & 0.002 \\
\hline BL 24 & 9.86 & 0.70 & 9.51 & 0.43 & 0.35 & 0.61 & 0.003 \\
\hline BL 33 & 7.58 & 0.77 & 7.18 & 0.63 & 0.40 & 0.57 & 0.005 \\
\hline MD 25 & 7.16 & 0.39 & 6.88 & 0.59 & 0.28 & 0.56 & 0.006 \\
\hline BL 34 & 8.25 & 0.65 & 7.93 & 0.47 & 0.32 & 0.56 & 0.006 \\
\hline BL 14 & 9.86 & 0.66 & 9.54 & 0.44 & 0.32 & 0.56 & 0.006 \\
\hline BL 16 & 11.63 & 0.69 & 11.30 & 0.57 & 0.33 & 0.52 & 0.010 \\
\hline MD 15 & 7.21 & 0.40 & 6.97 & 0.53 & 0.24 & 0.52 & 0.011 \\
\hline BL 22 & 6.76 & 0.69 & 6.46 & 0.53 & 0.30 & 0.50 & 0.014 \\
\hline BL 11 & 7.47 & 0.60 & 7.22 & 0.43 & 0.25 & 0.49 & 0.017 \\
\hline MD 21 & 8.90 & 0.53 & 8.65 & 0.55 & 0.25 & 0.47 & 0.021 \\
\hline BL 44 & 8.18 & 0.69 & 7.90 & 0.54 & 0.28 & 0.45 & 0.027 \\
\hline MD 36 & 11.47 & 0.62 & 11.16 & 0.75 & 0.31 & 0.45 & 0.027 \\
\hline MD 26 & 10.69 & 0.63 & 10.40 & 0.66 & 0.29 & 0.45 & 0.028 \\
\hline MD 12 & 7.19 & 0.57 & 6.95 & 0.55 & 0.24 & 0.43 & 0.033 \\
\hline MD 16 & 10.79 & 0.67 & 10.52 & 0.62 & 0.27 & 0.42 & 0.038 \\
\hline MD 11 & 8.91 & 0.55 & 8.68 & 0.57 & 0.23 & 0.41 & 0.044 \\
\hline MD 46 & 11.45 & 0.64 & 11.18 & 0.71 & 0.27 & 0.40 & 0.047 \\
\hline BL 23 & 8.34 & 0.89 & 8.04 & 0.67 & 0.30 & 0.38 & 0.057 \\
\hline BL 45 & 8.83 & 0.70 & 8.60 & 0.55 & 0.23 & 0.38 & 0.061 \\
\hline BL 12 & 6.77 & 0.69 & 6.53 & 0.63 & 0.24 & 0.38 & 0.063 \\
\hline BL 36 & 10.71 & 0.64 & 10.49 & 0.54 & 0.22 & 0.36 & 0.072 \\
\hline BL 13 & 8.33 & 0.78 & 8.08 & 0.62 & 0.25 & 0.36 & $<0.001$ \\
\hline BL 43 & 7.37 & 0.77 & 7.13 & 0.56 & 0.24 & 0.35 & $<0.001$ \\
\hline BL 26 & 10.71 & 0.09 & 10.49 & 0.07 & 0.22 & 0.35 & 0.071 \\
\hline MD 22 & 7.19 & 0.63 & 6.99 & 0.54 & 0.20 & 0.34 & 0.094 \\
\hline BL 41 & 6.19 & 0.56 & 6.02 & 0.49 & 0.17 & 0.33 & 0.104 \\
\hline MD 24 & 7.47 & 0.46 & 7.32 & 0.57 & 0.15 & 0.30 & 0.137 \\
\hline BL 46 & 10.72 & 0.63 & 10.55 & 0.60 & 0.17 & 0.27 & 0.177 \\
\hline BL 35 & 8.80 & 0.79 & 8.62 & 0.52 & 0.18 & 0.27 & 0.182 \\
\hline BL 31 & 6.11 & 0.57 & 5.97 & 0.59 & 0.14 & 0.26 & 0.205 \\
\hline MD 34 & 7.49 & 0.44 & 7.37 & 0.54 & 0.12 & 0.25 & 0.210 \\
\hline MD 44 & 7.48 & 0.42 & 7.38 & 0.52 & 0.10 & 0.23 & 0.250 \\
\hline MD 32 & 6.23 & 0.41 & 6.13 & 0.44 & 0.10 & 0.23 & 0.254 \\
\hline BL 42 & 6.40 & 0.52 & 6.29 & 0.52 & 0.11 & 0.22 & 0.266 \\
\hline MD 45 & 7.60 & 0.51 & 7.48 & 0.52 & 0.12 & 0.22 & 0.270 \\
\hline MD 35 & 7.62 & 0.53 & 7.50 & 0.56 & 0.12 & 0.21 & 0.285 \\
\hline MD 14 & 7.42 & 0.43 & 7.33 & 0.50 & 0.09 & 0.21 & 0.305 \\
\hline BL 32 & 6.45 & 0.56 & 6.36 & 0.43 & 0.09 & 0.19 & 0.353 \\
\hline MD 31 & 5.60 & 0.39 & 5.53 & 0.36 & 0.07 & 0.17 & 0.399 \\
\hline MD 42 & 6.20 & 0.42 & 6.15 & 0.38 & 0.05 & 0.14 & 0.490 \\
\hline MD 41 & 5.58 & 0.36 & 5.54 & 0.36 & 0.04 & 0.11 & 0.600 \\
\hline
\end{tabular}

Note: Effect size of the MD and BL dimensions of the permanent teeth between male and female. Tooth numbers coorelate to the numbers in Figure 1.

*Student's t test was used to compare the means between males and females.

Dean [6], sex hormone concentrations during development could relate to dental tis sue proportions in teeth forming at different moments. Smith et al. [26] obtained histological sections from molars and observed that males showed significantly greater dentine area, enamel-dentine junction length, and bi-cervical diameters in certain tooth types, while women presented significantly thicker average enamel. These results are consistent with the study of Saunders et al. [23], who noted that male canines and premolars have significantly more dentine than their female counterparts, as well as relatively more dentine with respect to overall crown size. The female canines and premolars have significantly more enamel relative to overall crown area than those of the males. Following this pattern, we presented some evidence that in humans, different dental groups might respond differently to the influence of sex chromosomes/hormones on crown development.

Another important aspect that should be taken into considerations is the ethnicity differences. Caucasian subjects presented some reduced dimensions when compared with African descendants. This should be taken into consideration in mixed populations, like Brazilians.

Table 3. Logistic regression analysis using ethnicity as covariates.

\begin{tabular}{|c|c|}
\hline Tooth Type & p-value \\
\hline BL 12 & 0.029 \\
\hline MD 15 & 0.005 \\
\hline BL 22 & 0.010 \\
\hline MD 16 & 0.021 \\
\hline MD 26 & 0.017 \\
\hline MD 32 & 0.150 \\
\hline MD 36 & 0.012 \\
\hline BL 45 & 0.029 \\
\hline MD 46 & 0.024 \\
\hline
\end{tabular}

Note: Using maximum measurements of the mesiodistal (MD) and buccolingual ( $\mathrm{BL}$ ) dimensions. Tooth numbers coorelate to the numbers in Figure 1.

In summary, our findings reinforced the magnitude of sexual dimorphism in tooth size, and, in addition, highlighted the differences in specific dental groups. The approach taken in this manuscript (oversimplified with only tooth size variant analyzed) is a limitation to properly assess the explanations for tooth-size dimorphism between males and females.

Thus, further investigations, based on genetic, evolutionary, and metabolic/hormonal reasons for sexual dimorphism, will hopefully further clarify the etiology of sexual dimorphism in tissue proportions and dental development. In conclusion, our results established the degree of sexual dimorphism in permanent teeth of Brazilian individuals.

Conflict of interest: There are no conflicts of interest to report. 


\section{References}

1. Studies of dental anomalies in a large group of school children. Küchler EC, Risso PA, Costa Mde C, Modesto A, Vieira AR. Arch Oral Biol. 2008 Oct;53(10):941-6. doi: 10.1016/j.archoralbio.2008.04.003. PMID: 18490001

2. Human sex chromosomes in oral and craniofacial growth. Alvesalo L. Arch Oral Biol. 2009 Dec;54 Suppl 1:S18-24. doi: 10.1016/j.archoralbio.2008.06.004. PMID: 18657798

3. Side of dental anomalies and taurodontism as potential clinical markers for cleft subphenotypes. Küchler EC, da Motta LG, Vieira AR, Granjeiro JM. Cleft Palate Craniofac J. 2011 Jan;48(1):103-8. doi: 10.1597/09-159. PMID: 20507240

4. Sex chromosomes and human growth. A dental approach. Alvesalo L. Hum Genet. 1997 Nov;101(1):1-5. PMID: 9385359

5. 47, XXX females, sex chromosomes, and tooth crown structure. Alvesalo L, Tammisalo E, Therman E. Hum Genet. 1987 Dec;77(4):345-8. PMID: 3692479

6. Sexual dimorphism in modern human permanent teeth. Schwartz GT, Dean MC. Am J Phys Anthropol. 2005 Oct;128(2):312-7. PMID: 15861426

7. Sexual dimorphism in primate evolution. Plavcan JM. Am J Phys Anthropol. 2001;Suppl 33:25-53. PMID: 11786990

8. The effect of prenatal factors on crown dimensions. Garn SM, Osborne RH, McCabe KD. Am J Phys Anthropol. 1979 Nov;51(4):665-78. PMID: 574721

9. Use of diagonal teeth measurements in predicting gender in a Turkish population. Karaman F. J Forensic Sci. 2006 May;51(3):630-5. PMID: 16696712

10. Gender determination by odontometrics in a Swedish population. Lund $\mathrm{H}$, Mörnstad H. J Forensic Odontostomatol. 1999 Dec;17(2):30-4. PMID: 10709560

11. Mesiodistal crown diameters of permanent teeth in Jordanians. Hattab FN, al-Khateeb $\mathrm{S}$, Sultan I. Arch Oral Biol. 1996 Jul;41(7):641-5. PMID: 9015564

12. Sex discrimination potential of buccolingual and mesiodistal tooth dimensions. Acharya $A B$, Mainali S. J Forensic Sci. 2008 Jul;53(4):790-2. doi: 10.1111/j.1556-4029.2008.00778.x. PMID: 18557797

13. Standards for mesiodistal and buccolingual crown size and height of primary molars in a sample of Spanish children. Barbería E, Suárez MC, Villalón G, Maroto M, García-Godoy F. Eur J Paediatr Dent. 2009 Dec;10(4):169-75. PMID: 20073541

14. The correlation of sexual dimorphism in tooth size and arch form. Haralabakis NB, Sifakakis I, Papagrigorakis M, Papadakis G. World J Orthod. 2006 Fall;7(3):254-60. PMID: 17009475

15. Comparison of tooth size and dental arch widths in contemporary Japanese and American preschool children. Yonezu T, Warren JJ, Bishara SE, Steinbock KL. World Journal of Orthodontics 2:356-360, 2001.

16. Mesiodistal crown diameters of the primary and permanent teeth in southern Chinese--a longitudinal study. Yuen KK, So LL, Tang EL. Eur J Orthod. 1997 Dec;19(6):721-31. PMID: 9458605

17. Correlations among crown diameters of human teeth. Moorrees CF, Reed RB. Arch Oral Biol. 1964 Nov-Dec;9:685-97. PMID: 14219519

18. Cohen J (1988) Statistical power analysis for the behavioral sciences (2nd ed.). Hillsdale, $\mathrm{NJ}$ : Lawrence Earlbaum Associates.

19. Determining dental sex dimorphism in South Indians using discriminant function analysis. Anuthama K, Shankar S, Ilayaraja V, Kumar GS, Rajmohan M, Vignesh. Forensic Sci Int. 2011 Oct 10;212(1-3):86-9. doi: 10.1016/j.forsciint.2011.05.018. PMID: 21664775

20. Odontometric sex assessment in Indians. Prabhu S, Acharya AB. Forensic Sci Int. 2009 Nov 20;192(1-3):129.e1-5. doi: 10.1016/j.forsciint.2009.08.008. PMID: 19744808

21. Sexual dimorphism in permanent teeth of modern Greeks. Zorba E, Moraitis K, Manolis SK. Forensic Sci Int. 2011 Jul 15;210(1-3):74-81. doi: 10.1016/j.forsciint.2011.02.001. PMID: 21371836

22. Genetic control of sexual dimorphism in tooth size. Garn SM, Lewis AB, Swindler DR, Kerewsky RS. J Dent Res. 1967 Sep-Oct;46(5):963-72. PMID: 5234039

23. Sexual dimorphism of the dental tissues in human permanent mandibular canines and third premolars. Saunders SR, Chan AH, Kahlon B, Kluge HF, FitzGerald CM. Am J Phys Anthropol. 2007 May;133(1):735-40. PMID: 17295299

24. Sexual dimorphism in the buccolingual tooth diameter. Garn SM, Lewis AB, Kerewsky RS. J Dent Res. 1966 Nov-Dec;45(6):1819. PMID: 5226551

25. Oral clefts and syndromic forms of tooth agenesis as models for genetics of isolated tooth agenesis. Vieira AR. J Dent Res. 2003 Mar;82(3):162-5. PMID: 12598542

26. Modern human molar enamel thickness and enamel-dentine junction shape. Smith TM, Olejniczak AJ, Reid DJ, Ferrell RJ, Hublin JJ. Arch Oral Biol. 2006 Nov;51(11):974-95. PMID: 16814245 